\title{
The paediatric suprasellar cistern as an important CT review area
}

\section{Dahya MB BCh, FCRad (Diag) SA \\ $S$ Andronikou MB BCh, FCRad (Diag) SA, FRCR \\ Department of Radiology University of Cape Town and Red Cross Children's Hospital}

\section{Abstract}

Pathology affecting the suprasellar cistern is varied in paediatric neuroradiology practice. Although MRI is the imaging modality of choice for lesions of the suprasellar cistern, abnormali- ties can be detected on CT with knowledge of the normal anatomy and a sound approach to the possible pathological entities. We present our approach to pathology affecting the suprasellar cistern and highlight this using various cases seen at our institution in the recent past.

\section{Introduction}

In modern radiology practice it is accepted that the suprasellar and sellar regions are best imaged using MRI. ${ }^{1}$ However, in both the First and ThirdWorld, obtaining an MRI scan is often difficult due to the constraints of cost and availability. CT is fairly ubiquitous in modern times and is often the first imaging modality used in paediatric patients requiring neuroradiological evaluation. Pathology is often subtle on CT compared with MRI and careful review of images by the radiologist is necessary to make accurate diagnoses. The suprasellar cistern is an area that warrants review as it can be involved in a number of pathological processes.

Our approach to pathology affecting the suprasellar cistern is based on the normal anatomical structures adjacent to and within it (Table I).

\section{Fig. 1}

Normal suprasellar cistern on contrast-enhanced CT showing the characteristic pentagonal shape. ${ }^{2}$ The vessels comprising the circle of Willis are clearly seen. Note the optic chiasm (long black arrow) and the contrastenhancing normal infundibular stalk posterior to the chiasm (white arrow).

\begin{tabular}{|c|c|c|}
\hline & Structure & Pathology \\
\hline \multirow[t]{6}{*}{ Relations } & Inferior: pituitary gland/sella & $\begin{array}{l}\text { - Craniopharyngioma/ Rathke cleft cyst (embryological rests along } \\
\text { vestigeal craniopharygeal duct) } \\
\text { - Pituitary adenoma (rare) }\end{array}$ \\
\hline & Superior: hypothalamus & - Hamartoma \\
\hline & & - Glioma \\
\hline & Anterior: gyrus rectus & $\begin{array}{l}\text { - Granuloma } \\
\text { - Glioma }\end{array}$ \\
\hline & Posterior: pons & - Glioma \\
\hline & Lateral: medial temporal lobes & - Uncal herniation \\
\hline \multirow[t]{6}{*}{ Contents } & Circle of Willis & - Aneurysms \\
\hline & Meninges & - Inflammatory, infective or neoplastic thickening / nodularity \\
\hline & Optic chiasm & - Glioma \\
\hline & Infundibulum/stalk & - Langerhans cell histiocytosis \\
\hline & & - Germ cell tumour \\
\hline & & - Metastases \\
\hline
\end{tabular}




\section{PICTORIAL REVIEW}

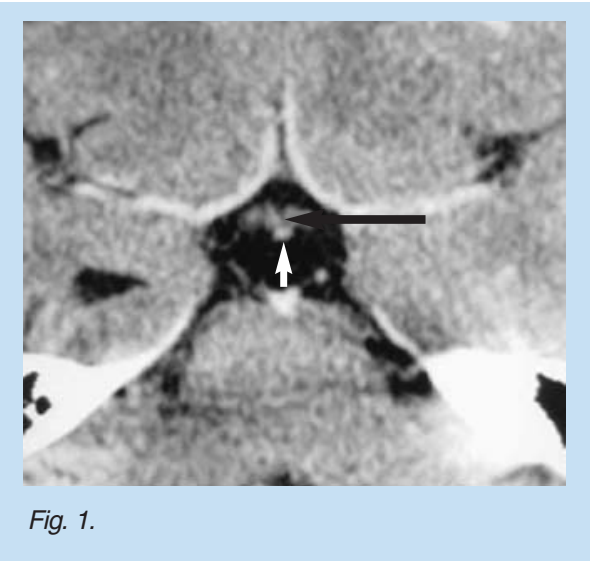

Fig. 2

Normal suprasellar cistern seen on contrast-enhanced CT showing the normal hypothalamus within it (black arrow).

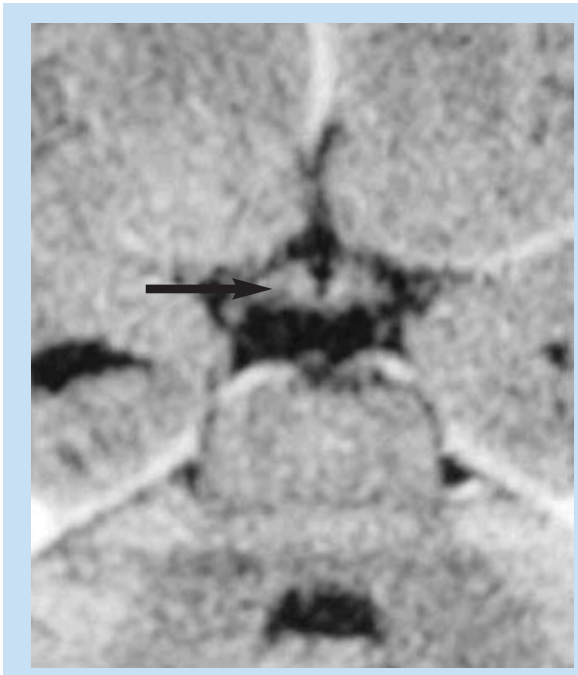

Fig. 2.

\section{Fig. 3}

Craniopharyngiomas in two separate patients on contrast-enhanced $\mathrm{CT}$ with dense calcification within the suprasellar cistern. Solid (thin black arrow) and cystic (open black arrow) components are present in (b), with hydrocephalus.

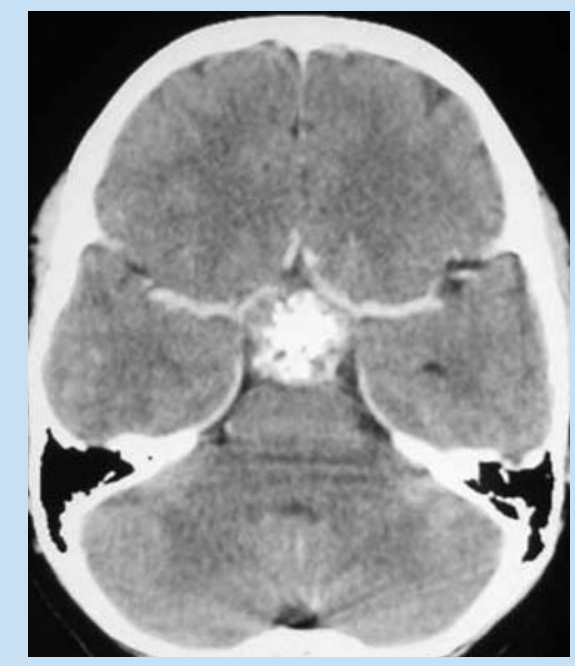

Fig. 3a.

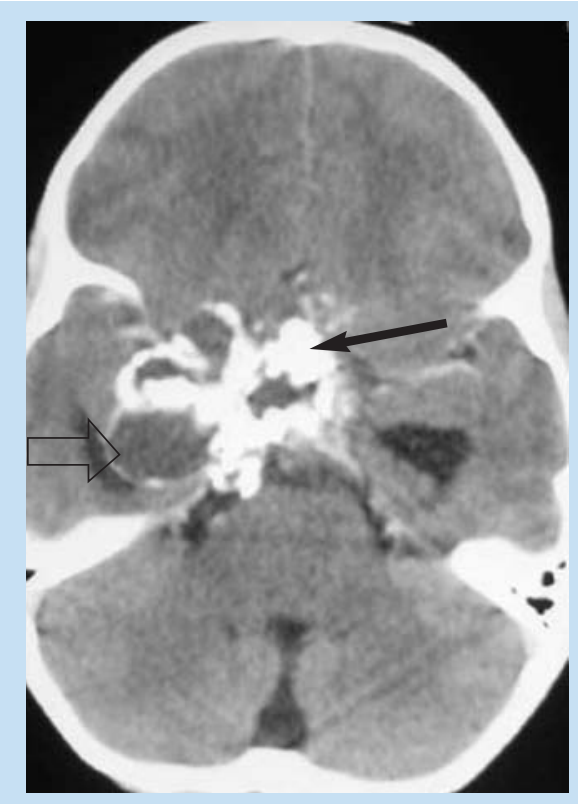

Fig. $3 b$.

\section{Fig. 4}

A more subtle craniopharyngioma with peripheral rim calicification (white arrow) seen pre-contrast administration (a). Rim enhancement is seen post-contrast (white arrow) (b). Note that the bulk of the tumour is isodense to grey-matter.

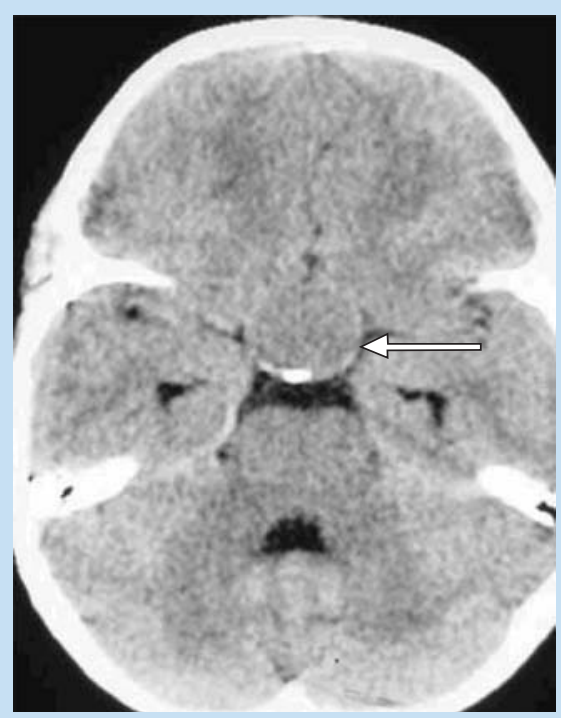

Fig. $4 a$.

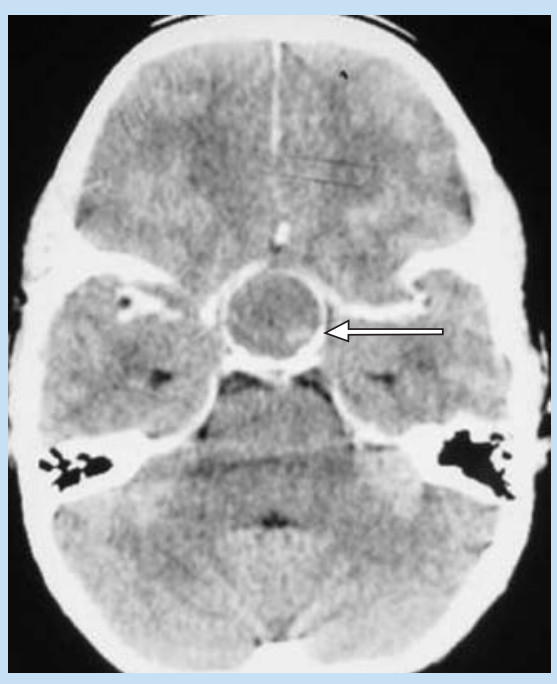

Fig. $4 b$.

Fig. 5

Post-contrast CT showing a tubercinerium hamartoma. Note the nonenhancing subtle abnormality (white arrow). The child presented with gelastic seizures.

\section{Fig. 6}

A pontine glioma encroaching on the posterior suprasellar cistern on contrast-enhanced CT. Note the nonenhancement of the tumour. Partial 


\section{PICTORIAL REVIEW}

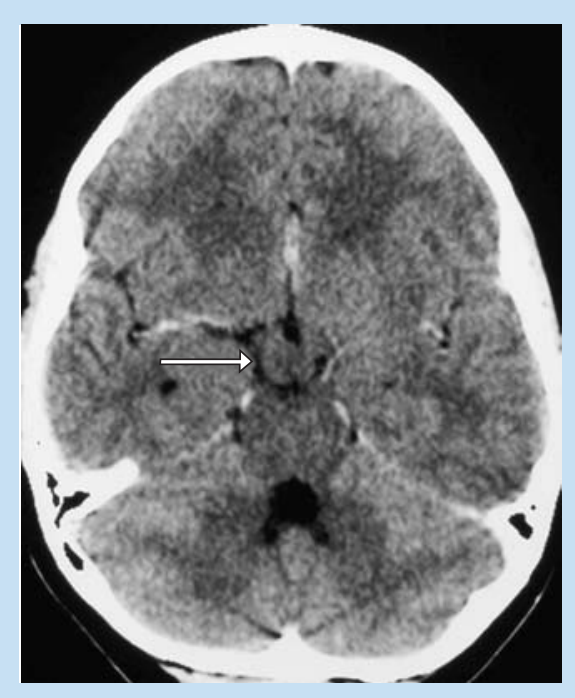

Fig. 5.

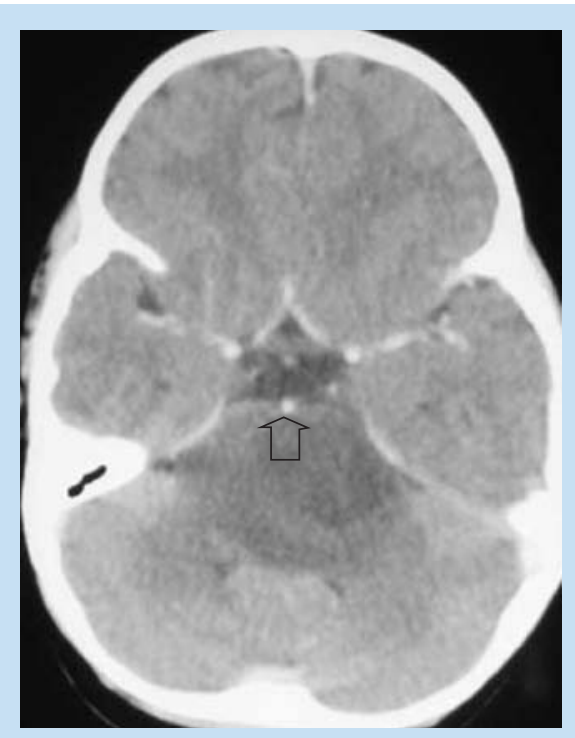

Fig. 6.

encasement of the basilar artery (open black arrow) is an important clue to detection. $^{3}$

\section{Fig. 7}

Haemorrhage from a suprasellar aneurysm on: (i) non-contrast CT and the aneurysm viewed from above on: (ii) SSD (shaded-surface display) CT angiogram of the circle of Willis (open white arrow).

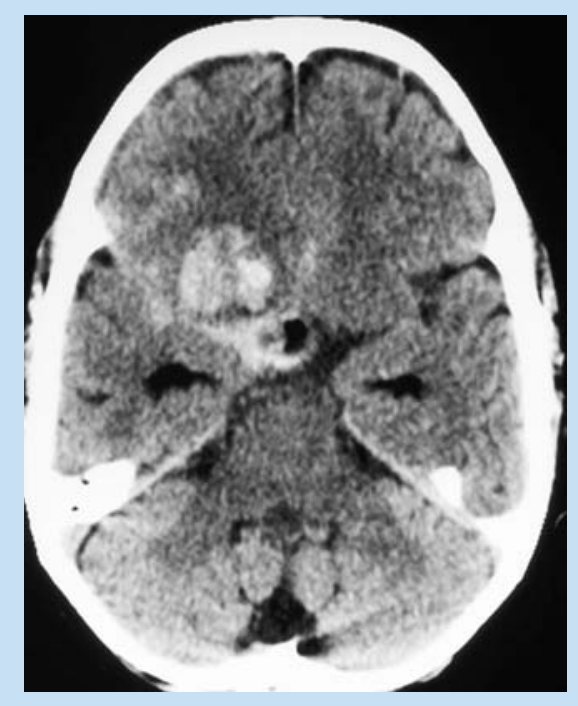

Fig. $7 a$.

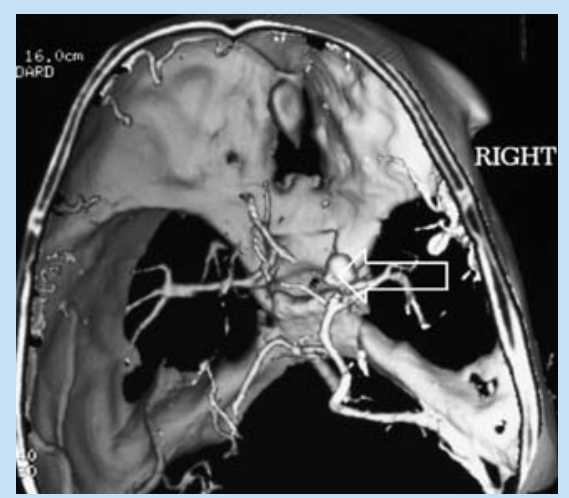

Fig. $7 b$.

\section{Fig. 8}

A meningeal granuloma within the suprasellar cistern (white arrows) pre (a) and post (b) contrast. Intense post-contrast ring-enhancement is present. Microbiological studies confirmed the diagnosis of tuberculosis.

\section{Fig. 9}

A patient with confirmed tuberculous meningitis with intense meningeal enhancement within the suprasellar cistern (white arrow) and bilateral extension into the Sylvian fissures and the ambient-wing cisterns bilaterally. Note the complicating hydrocephalus.

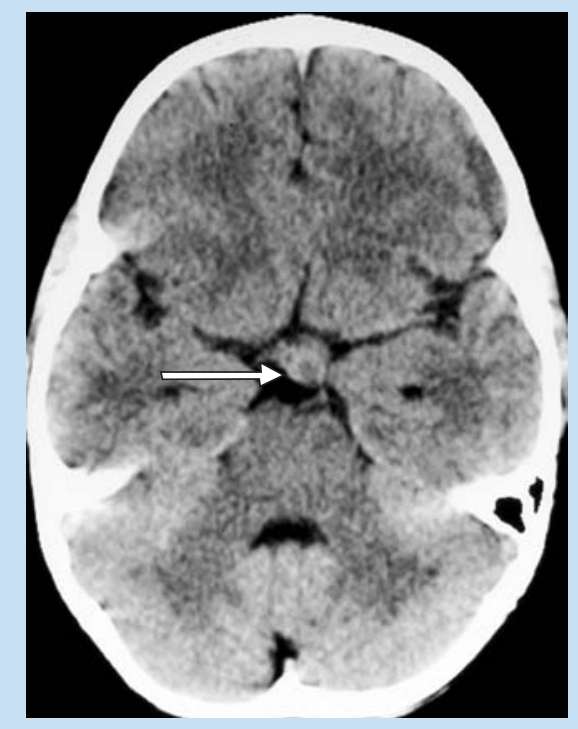

Fig. $8 a$.

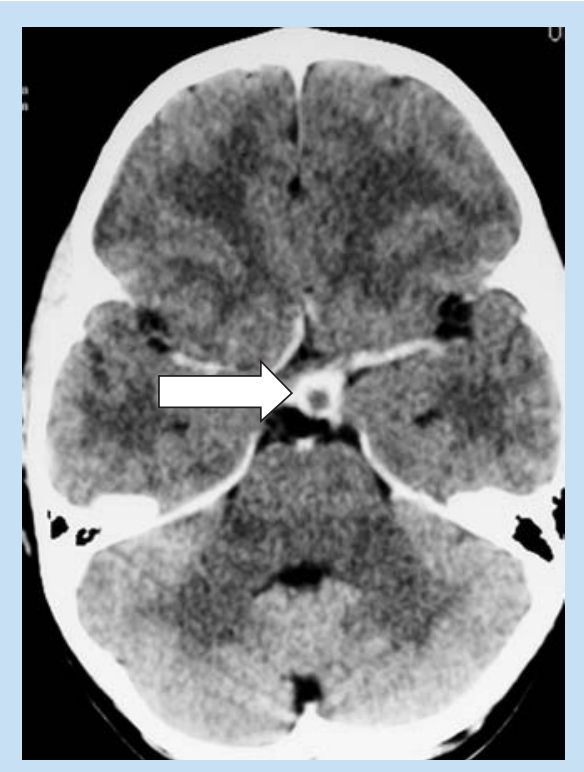

Fig. $8 b$

Fig. 10

Post-contrast CT showing a typical homogeneously enhancing optic chiasm glioma (white arrow). The patient has neurofibromatosis Type One.

\section{Fig. 11}

A germ-cell tumour with hyperdensity of the tumour and calcification (open black arrow) pre-contrast 


\section{PICTORIAL REVIEW}

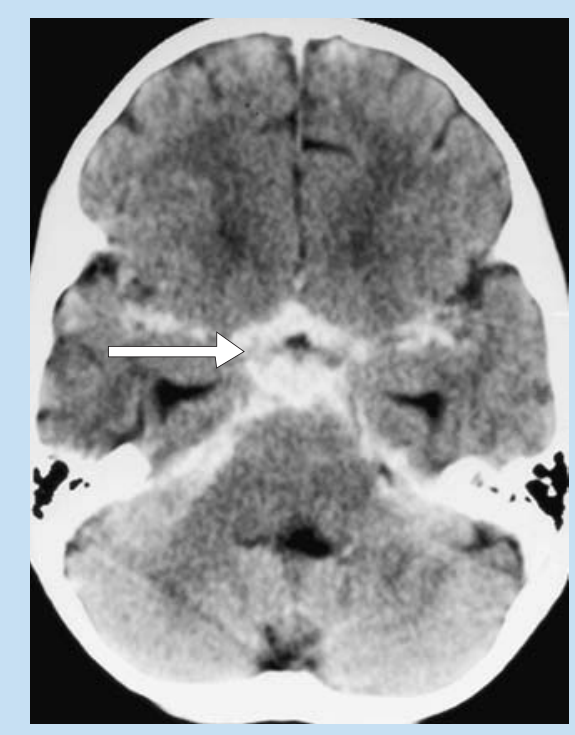

Fig. 9.

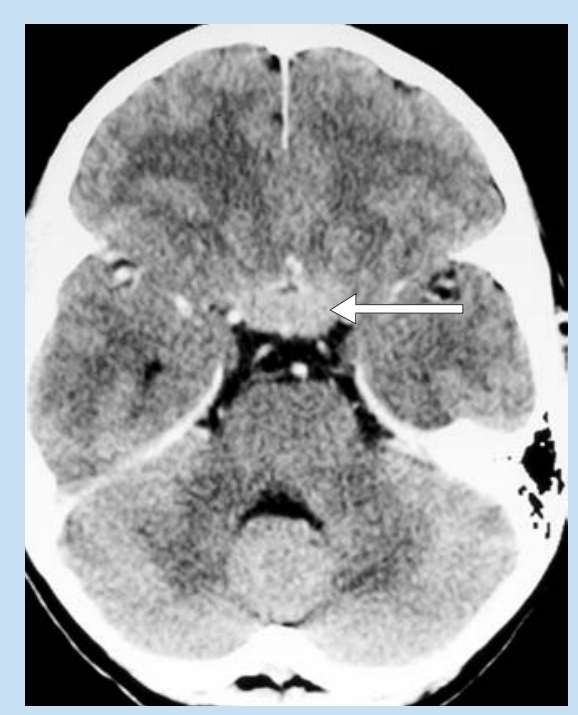

Fig. 10.

(a) and strong enhancement postcontrast administration (b). Hydrocephalus is also present.

\section{Fig. 12}

A patient with proven tuberculous meningitis with thickening and enhancement of the infundibular stalk $^{4}$ (open black arrows). Similar findings can be noted with Langerhans-cell histiocytosis. ${ }^{5}$ Of note is that this patient did not have diabetes

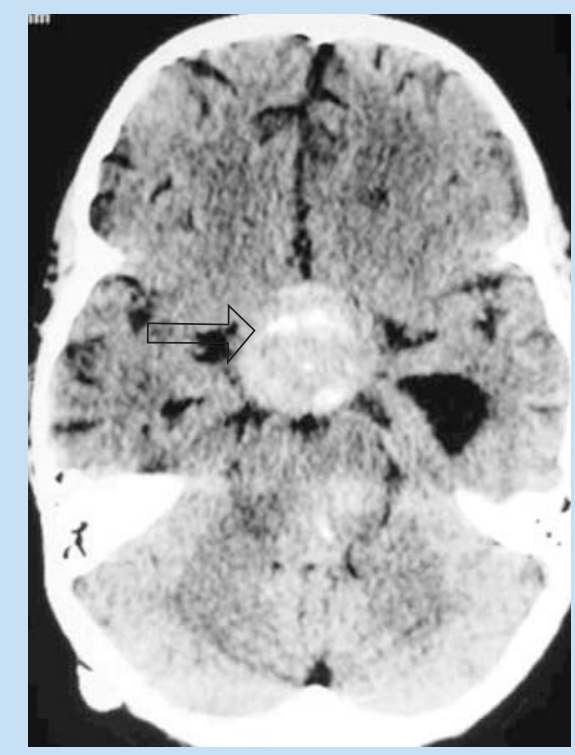

Fig. 11a.

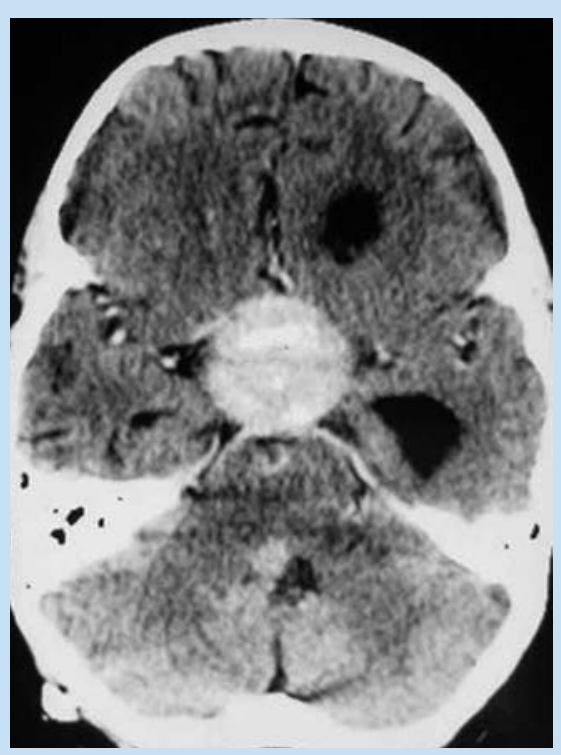

Fig. $11 b$.

insipidus, which commonly occurs with infundibular stalk lesions.

\section{References}

1. Connor SEJ, Penney CC. MRI in the differential diagnosis of a sellar mass. Clin Radiol 2003; 58: 20-31.

2. Kuuliala J. The normal suprasellar subarachnoid space in computed tomography. Clin Radiol 1980; 31: 155-159.

3. Naidich P, Zimmerman RA. Primary brain tumours in children. Semin Roentgenol 1984 19: $100-114$.

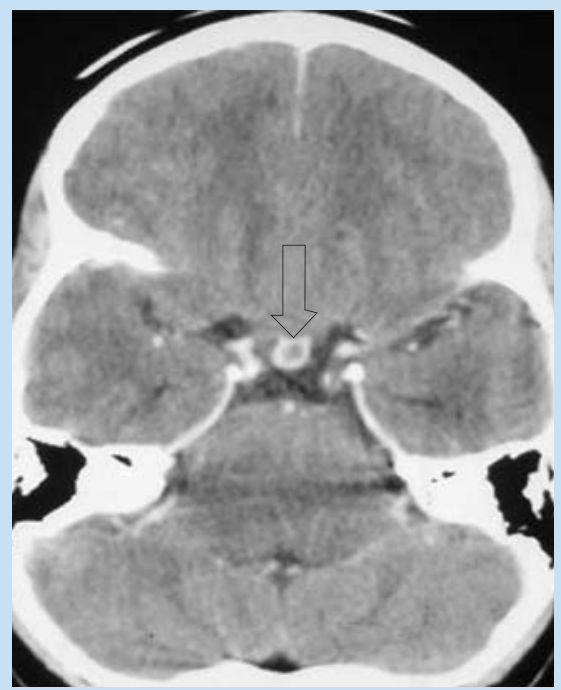

Fig. $12 a$.

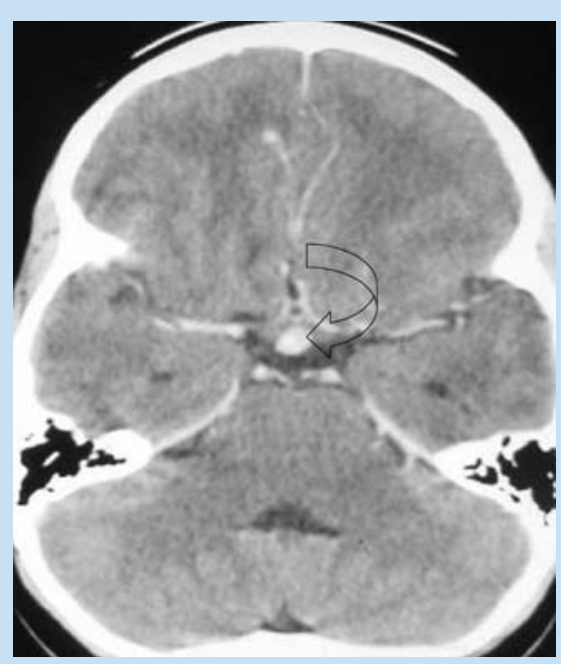

Fig. $12 b$.

4. Manelfe C, Louvet JP. Computed tomography in diabetes insipidus. J Comput Assist Tomogr 1979; 3: 306-309.

5. Schmitt S, Wichmann W, Martin E, Zachmann M, Schoenle EJ. Pituitary stalk thickening with diabetes insipidus preceding typical manifestations of Langerhans cell histiocytosis in children. Eur J Paediatr 1993; 152: 399-401.

6. Andronikou S, Furlan G, Fieggen AG, Wilmhurst J. Two unusual causes of pituitary stalk thickening in children without clinical features of diabetes insipidus. Pediatr Radiol 2003; 33: 499-502. 